\title{
Identification of novel peptides that stimulate human neutrophils
}

\author{
Geon Ho Bae ${ }^{1 *}$, Ha Young Lee ${ }^{1,2 *}$, Young Su Jung ${ }^{1,2}$, \\ Jae Woong Shim ${ }^{1}$, Sang Doo Kim ${ }^{1,2}$, \\ Suk-Hwan Baek', Jae Young Kwon', \\ Joon Seong Park ${ }^{4}$ and Yoe-Sik Bae ${ }^{1,2,5}$ \\ ${ }^{1}$ Department of Biological Sciences \\ Sungkyunkwan University \\ Suwon 440-746, Korea \\ ${ }^{2}$ Mitochondria Hub Regulation Center \\ College of Medicine, Dong-A University \\ Busan 602-714, Korea \\ ${ }^{3}$ Department of Biochemistry and Molecular Biology \\ Yeungnam University \\ Daegu 705-030, Korea \\ ${ }^{4}$ Department of Hematology-Oncology \\ Ajou University School of Medicine \\ Suwon 443-721, Korea \\ ${ }^{5}$ Corresponding author: Tel, 82-31-290-5914; \\ Fax, 82-31-290-7015; E-mail, yoesik@skku.edu \\ ${ }^{*}$ These authors contributed equally to this work. \\ http://dx.doi.org/10.3858/emm.2012.44.2.008
}

Accepted 14 November 2011

Available Online 16 November 2011

Abbreviations: FPR, formyl peptide receptor; GMMWAI, GlyMet-Met-Trp-Ala-Ile-CONH ${ }_{2} ; \mathrm{IP}_{3}$, inositol-1,4,5-triphosphate; MMHWAM, Met-Met-His-Trp-Ala-Met-CONH ${ }_{2}$; MMHWFM, Met-Met-His-Trp-Phe-Met-CONH${ }_{2}$; PLC, phospholipase C; PS-SPCL, positional scanning synthetic peptide combinatorial library; PTX, pertussis toxin

\begin{abstract}
Neutrophils play a key role in innate immunity, and the identification of new stimuli that stimulate neutrophil activity is a very important issue. In this study, we identified three novel peptides by screening a synthetic hexapeptide combinatorial library. The identified peptides GMMWAI, MMHWAM, and MMHWFM caused an increase in intracellular $\mathrm{Ca}^{2+}$ in a concentration-dependent manner via phospholipase $\mathrm{C}$ activity in human neutrophils. The three peptides acted specifically on neutrophils and monocytes and not on other non-leu-
\end{abstract}

kocytic cells. As a physiological characteristic of the peptides, we observed that the three peptides induced chemotactic migration of neutrophils as well as stimulated superoxide anion production. Studying receptor specificity, we observed that two of the peptides (GMMWAI and MMHWFM) acted on formyl peptide receptor (FPR)1 while the other peptide (MMHWAM) acted on FPR2. Since the three novel peptides were specific agonists for FPR1 or FPR2, they might be useful tools to study FPR1- or FPR2-mediated immune response and signaling.

Keywords: calcium; chemotaxis; neutrophils; peptide library; peptides; receptors, formyl peptide

\section{Introduction}

Neutrophils play an important role in the regulation of immune responses, especially in the innate immune response (Kumar and Sharma, 2010). Neutrophils are recruited to infected areas or sites of injury according to a chemoattractant gradient (Borregaard, 2010; Kumar and Sharma, 2010). Recruited neutrophils can be activated by extracellular stimuli, resulting in the production of several reactive oxygen species (Dahlgren and Karlssson, 1999; Walther et al., 2000; Tiffany et al., 2001). It is a critical aspect of resting neutrophils that they must be activated for host defense. The activation of neutrophils can be induced by various different stimuli, including pathogen-derived molecules and several chemoattractants (Walther et al., 2000; Tiffany et al., 2001; Sabroe et al., 2003; Kobayashi, 2008). Among these, chemoattractants, including several chemokines that regulate the activities of neutrophils, have received much attention over the last decade. These chemoattractants bind to specific cell surface receptors, which are coupled to pertussis toxin (PTX)-sensitive G-protein(s), resulting in intracellular $\mathrm{Ca}^{2+}$ mobilization, cell migration, exocytosis, adhesion, and generation of bioactive lipids and/or reactive oxygen species (Walther et al., 2000; Tiffany et al., 2001; Kobayashi, 2008). Keeping in mind the important roles of chemoattractants in 
neutrophils, the identification of new chemoattractants and the characterization of their mechanisms of action are very much needed.

For the identification of new bioactive molecules, various different types of molecular diversities can be used. Positional scanning synthetic peptide combinatorial library (PS-SPCL), which is an easy and powerful tool for identifying peptide sequences in certain biological reactions, was developed by Houghten et al. (Houghten et al., 1991). Many groups have used this method for various purposes, including the identification of human immunodeficiency virus protease inhibitors, interleukin-8-specific antagonists, inhibitor for nuclear factor of activated $\mathrm{T}$ cells, and ligands for opioid receptors (Owens et al., 1991; Hayashi et al., 1995; Dooley et al., 1998; Aramburu et al., 1999). Further, we already identified several bioactive hexapeptide that stimulates superoxide anion production or arachidonic acid release by screening hexapeptide combinatorial libraries (Bae et al., 2001, 2003).

Here, we adopted the PS-SPCL method to identify novel peptides that can stimulate a $\mathrm{Ca}^{2+}$ increase in human neutrophils. We found that the peptides Gly-Met-Met-Trp-Ala-Ile-CONH $\mathrm{CHMWAI}_{2}$, Met-Met-His-Trp-Ala-Met-CONH 2 (MMHWAM), and Met-Met-His-Trp-Phe-Met-CONH ${ }_{2}$ (MMHWFM) can stimulate human neutrophils, resulting in intracellular $\mathrm{Ca}^{2+}$ increase. We also investigated the functional roles of the peptides and the target receptors of these three peptides.

\section{Results}

\section{Identification of peptides that stimulate $\mathrm{Ca}^{2+}$ increase in human neutrophils}

A total of 114 peptide pools (around 47 million peptides) from hexapeptide PS-SPCLs were screened to identify peptides that stimulate a $\mathrm{Ca}^{2+}$ increase in human neutrophils. As shown in Figure 1 , we observed that each amino acid that was fixed at each position induced different levels of $\mathrm{Ca}^{2+}$ increase from the initial screening. The most active peptides at each position were as follows: Met (M) or Gly $(G)$ in the 1st position, Met (M) in 2nd, His $(H)$ or Met $(M)$ in 3rd, Trp $(W)$ in 4th, Ala $(A)$ in 5th, and Met $(\mathrm{M})$ or lle $(\mathrm{I})$ in 6th.

\section{Peptides-induced $\mathrm{Ca}^{2+}$ increase is mediated via G-proteins and PLC}

Based on the results of the initial screening of the peptide libraries, we synthesized three representative hexapeptides (GMMWAI, MMHWAM, and MMHWFM) and confirmed that stimulation of neutrophils with various concentrations of these three peptides induced a $\mathrm{Ca}^{2+}$ increase in a concentration-dependent manner with maximal activity of 0.5-5 $\mu \mathrm{M}$ (Figures $2 \mathrm{~A}-2 \mathrm{C}$ ).

Intracellular $\mathrm{Ca}^{2+}$ increase can be induced by several different pathways. Firstly, the activation of some types of $\mathrm{Ca}^{2+}$ channels elicits intracellular $\mathrm{Ca}^{2+}$ increase in leukoyctic cells (Berridge, 1993; Burnashev, 1998; Zhu et al., 2010). Since we observed that the three novel peptides increased intracellular $\mathrm{Ca}^{2+}$ levels in human neutrophils, we examined the involvement of the cell surface $\mathrm{Ca}^{2+}$ channel. For this, we used several different $\mathrm{Ca}^{2+}$ channel-selective inhibitors. As shown in Figure 2D, MMHWAM-induced intracellular $\mathrm{Ca}^{2+}$ increases were not affected by preincubating human neutrophils with $1 \mu \mathrm{M}$ nifedifine (voltage-sensitive $\mathrm{L}$ type $\mathrm{Ca}^{2+}$ channel inhibitor), $10 \mu \mathrm{M}$ diltiazem (voltage-sensitive $\mathrm{L}$ type $\mathrm{Ca}^{2+}$ channel inhibitor), and $10 \mu \mathrm{M}$ SK\&F. These results indicate that
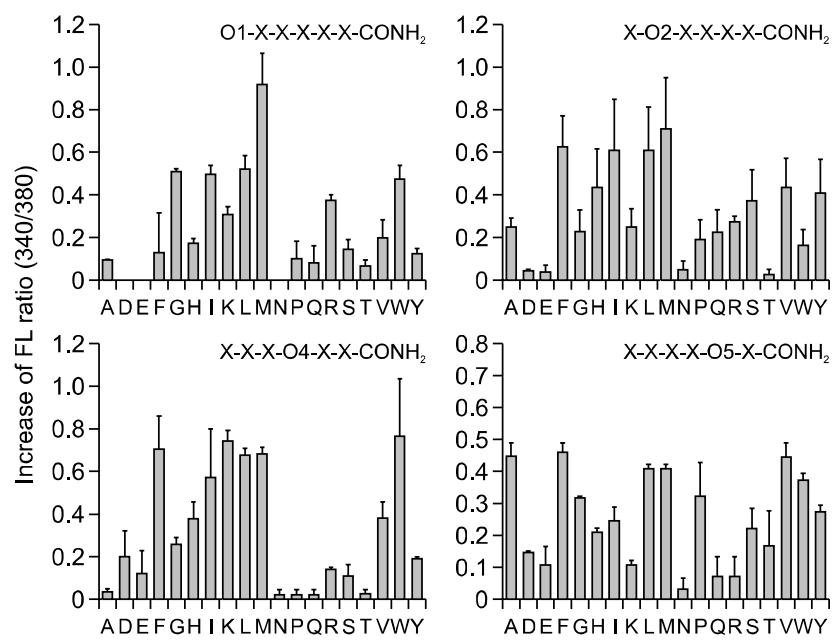

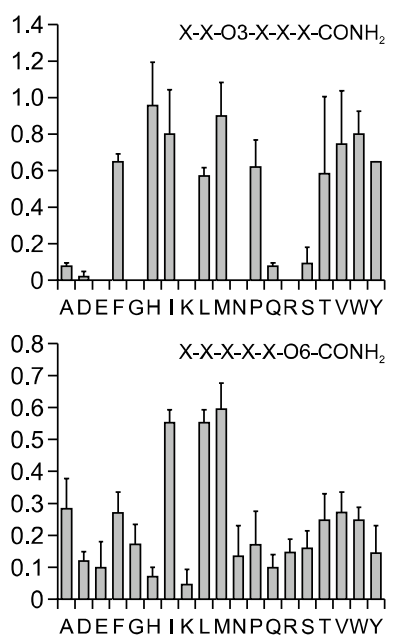

Figure 1. Initial screening of PSSPCLs for peptides stimulating intracellular $\mathrm{Ca}^{2+}$ increase in human neutrophils. Each panel shows the results obtained with the peptide pools with known amino acids at each of the six positions of the hexapeptide. The six positions were individually defined $(01,02$ etc.) by one of the $19 \mathrm{~L}$-amino acids. The remaining five positions consist of mixtures $(X)$ of the $19 \mathrm{~L}$-amino acids (except for cysteine). Human neutrophils $\left(1 \times 10^{6}\right.$ cells/assay) were used for each assay. Fluorescence ratio (340/38) was monitored as described under Methods. The results represent one of three independent experiments. 

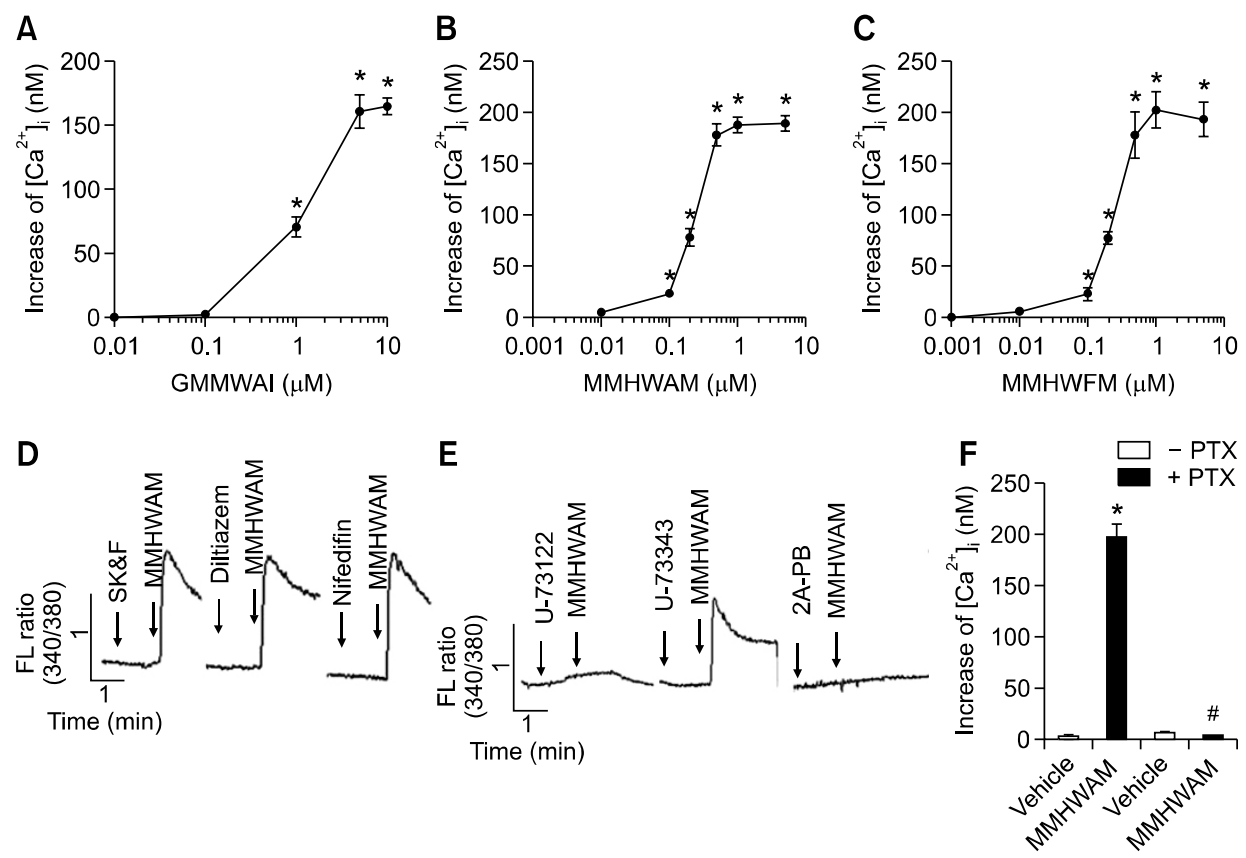

Figure 2. Effects of peptides on $\mathrm{Ca}^{2+}$ increase in human neutrophils. Fura-2-loaded human neutrophils were stimulated with various concentrations of GMMWAI, MMHWAM, and MMHWFM. The change in $340 \mathrm{~nm} / 380 \mathrm{~nm}$ was monitored. The peak level of the increase in $\mathrm{Ca}^{2+}$ was monitored. Data are presented as means \pm S.E. of four independent experiments (A-C). Fura-2-loaded human neutrophils were stimulated with $5 \mu M$ MMHWAM in the absence or presence of SK\&F $(10 \mu \mathrm{M})$, diltiazem $(1 \mu \mathrm{M})$, nifidifin $(1 \mu \mathrm{M})$, U-73122 $(5 \mu \mathrm{M}), \mathrm{U}-73343(5 \mu \mathrm{M})$, and 2A-PB $(5 \mu \mathrm{M})$. The change in $340 \mathrm{~nm} / 380$ $\mathrm{nm}$ was monitored. The results are representative of three independent experiments $(D, E)$. Human neutrophils were preincubated with or without $1 \mu \mathrm{g} / \mathrm{ml}$ of PTX for $4 \mathrm{~h}$, after which fura-2 was loaded into the cells. Fura-2-loaded cells were stimulated with $5 \mu \mathrm{M}$ MMHWAM. The peak level of the increase in $\mathrm{Ca}^{2+}$ was monitored. Data are presented as means \pm S.E. of three independent experiments $(\mathrm{F})$. ${ }^{*}, P<0.05$, compared with the value obtained from the vehicle control;,$P<0.05$, significantly different from the -PTX control.

MMHWAM increased $\mathrm{Ca}^{2+}$ concentration independent of the $\mathrm{Ca}^{2+}$ channel-dependent pathway in human neutrophils.

Another pathway for intracellular $\mathrm{Ca}^{2+}$ increase is mediated by the activation of PLC (Noh et al., 1995; Rhee, 2001). To determine the role of PLC in the MMHWAM-induced $\mathrm{Ca}^{2+}$ increase, we pretreated cells with a specific PLC inhibitor, U-73122, or with its inactive analogue, U-73343. As shown in Figure 2E, U-73122 but not U-73343 completely inhibited the MMHWAM-induced $\mathrm{Ca}^{2+}$ increase. 2-aminoethoxydiphenyl borate (2-APB), which is used to block $\mathrm{IP}_{3}$ receptor in cells (Maruyama et al., 1997), also completely inhibited the MMHWAMinduced $\mathrm{Ca}^{2+}$ increase in human neutrophils (Figure $2 \mathrm{E}$ ). These results indicate that MMHWAM stimulated $\mathrm{Ca}^{2+}$ increase via PLC activation in human neutrophils. MMHWAM resulted in intracellular $\mathrm{Ca}^{2+}$ elevation not only in the presence of extracellular $\mathrm{Ca}^{2+}$ but also in the absence of extracellular $\mathrm{Ca}^{2+}$ (data not shown), supporting that the peptide induced $\mathrm{Ca}^{2+}$ increase via the activation of PLC in human neutrophils.

We also examined the effect of PTX, a specific inhibitor of $G_{i / o}$ type $G$ proteins, on the peptidesinduced $\mathrm{Ca}^{2+}$ increase. When human neutrophils were preincubated with $1 \mu \mathrm{g} / \mathrm{ml}$ of PTX prior to stimulation with MMHWAM, the peptides-induced $\mathrm{Ca}^{2+}$ increase was almost completely inhibited (Figure 2F). These results indicate that MMHWAM stimulated $\mathrm{Ca}^{2+}$ increase via PTX-sensitive $\mathrm{G}$ proteins. We also observed that the other two peptides (GMMWAI and MMHWFM) stimulated $\mathrm{Ca}^{2+}$ increase via Gi protein and PLC but not the $\mathrm{Ca}^{2+}$ channel (data not shown).

\section{Leukocyte-specific effects of the novel peptides}

The fact that GMMWAI, MMHWAM, and MMHWFM stimulated human neutrophils led us to examine the effects of the peptides on other leukocytes such as monocytes. Stimulation of monocytes with the three peptides resulted in $\mathrm{Ca}^{2+}$ increase (Figure 3). The three peptides also enhanced $\mathrm{Ca}^{2+}$ levels in monocytes with a similar concentration dependency as observed for the $\mathrm{Ca}^{2+}$ increase (Figure 3 and data not shown). Next, we examined the effects of GMMWAI, MMHWAM, and MMHWFM on intracellular $\mathrm{Ca}^{2+}$ release in several non-leukocytic cell lines. NIH3T3 $(\mathrm{NIH}$ Swiss mouse embryo fibroblast), 3Y1 (Rat embryonic fibroblast), 3T3L1 (preadipocyte), and PC12 

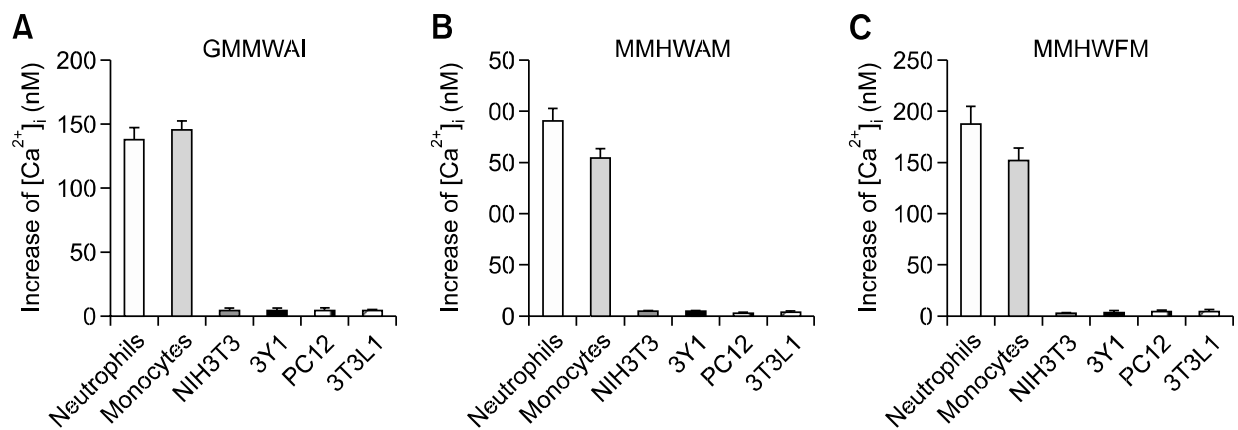

Figure 3. Cell specificity of the peptides. Prepared human primary monocytes, neutrophils, NIH3T3, 3Y1, 3T3L1, and PC12 cells were loaded with fura-2 and stimulated with three peptides at a concentration of $10 \mu \mathrm{M}$. The peak level of the $\mathrm{Ca}^{2+}$ increase was recorded. Data are presented are means \pm S.E. from at least three independent experiments.
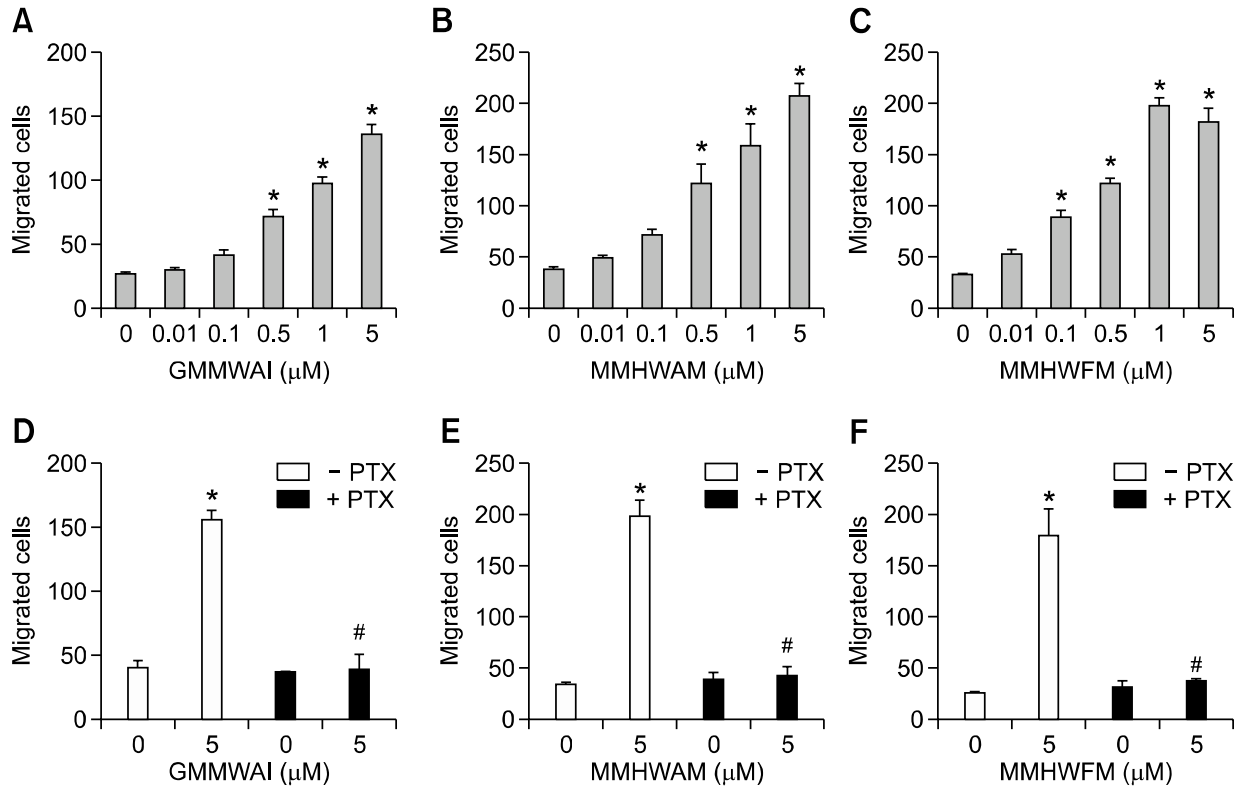

Figure 4. Chemotactic effects of the peptides. Assays were performed using a modified Boyden chamber assay. Isolated human neutrophils $\left(1 \times 10^{6}\right.$ cells $/ \mathrm{ml}$ of serum-free RPMI 1640) were added to the upper wells of a 96-well chemotaxis chamber, and migration across the polycarbonate membrane with $3-\mu \mathrm{m}$ pore size was assessed after $1.5 \mathrm{~h}$ of incubation at $37^{\circ} \mathrm{C}(\mathrm{A}-\mathrm{C})$. Human neutrophils were incubated with or without $1 \mu \mathrm{g} / \mathrm{ml}$ of PTX for $4 \mathrm{~h}$. Then, the cells were used for chemotaxis assay using $5 \mu \mathrm{M}$ GMMWAI, MMHWAM, or MMHWFM (D-F). The numbers of migrated cells were determined by counting them in high power field (400X). The data are presented as mean \pm S.E. of three independent experiments, each performed in duplicate. ${ }^{*} P$ $<0.05$, compared with the value obtained from the vehicle control; ${ }^{*} P<0.05$, significantly different from the -PTX control.

(rat adrenal pheochromocytoma) cells showed no response to the three peptides in terms of $\mathrm{Ca}^{2+}$ increase (Figure 3). From these results, we suggest that the effects of the three peptides were specific to human leukocytes.

\section{Chemotactic effects of the novel peptides on human neutrophils}

We demonstrated that the novel peptides stimulated $\mathrm{Ca}^{2+}$ increase in human neutrophils in a PTX-sensitive manner. Since peptides-induced and chemoattractant-induced neutrophil activation are similar to each other, we investigated whether or not the peptides exhibit chemotactic activity on human neutrophils. GMMWAI, MMHWAM, and MMHWFM induced migration of human neutrophils within a 0.1-5 $\mu \mathrm{M}$ concentration, showing concentration response curves (Figures $4 \mathrm{~A}-4 \mathrm{C}$ ). This implies that the three novel peptides induced chemotaxis in human neutrophils.

Various extracellular stimuli, including many chemoattractants, activate neutrophils via PTXsensitive G-protein(s) (Badolato et al., 1995; Bae et al., 1999). Here, we also examined the involvement of PTX-sensitive G-protein(s) on peptide-in- 
duced neutrophil chemotaxis. Preincubation of human neutrophils with PTX $(1 \mu \mathrm{g} / \mathrm{ml})$ for $4 \mathrm{~h}$ caused complete inhibition of peptides-induced neutrophil chemotaxis (Figure 4D-F). The results indicate that GMMWAI, MMHWAM, and MMHWFM stimulated human neutrophil chemotaxis via PTXsensitive G-protein(s).

\section{MMHWAM and MMHWFM but not GMMWAl stimulate superoxide anion production from human neutrophils}

In this study, we found that the three novel peptides stimulated not only intracellular $\mathrm{Ca}^{2+}$ increase but also chemotactic migration via PTX-sensitive G-protein(s). Neutrophils perform an important role in the innate immune response by producing a large amount of superoxide anion after stimulation with extracellular stimuli (Dahlgren and Karlsson,
1999). Superoxide anion is a well-known method of killing invading pathogens employed by human neutrophils (Rossi, 1986; Segal and Abo, 1993; Dahlgren and Karlsson, 1999). Here, we also tested the effects of the three novel peptides on the generation of superoxide anion from human neutrophils. Stimulation of human neutrophils with various concentrations of GMMWAI failed to induce superoxide anion production (Figure 5A). However, the other two novel peptides (MMHWAM and MMHWFM) strongly increased superoxide anion production from human neutrophils (Figures $5 \mathrm{~B}$ and $5 \mathrm{C})$.

\section{Novel peptides stimulate formyl peptide receptor (FPR)1 or FPR2}

The three peptides showed similar effects on human neutrophils, in terms of $\mathrm{Ca}^{2+}$ increase and
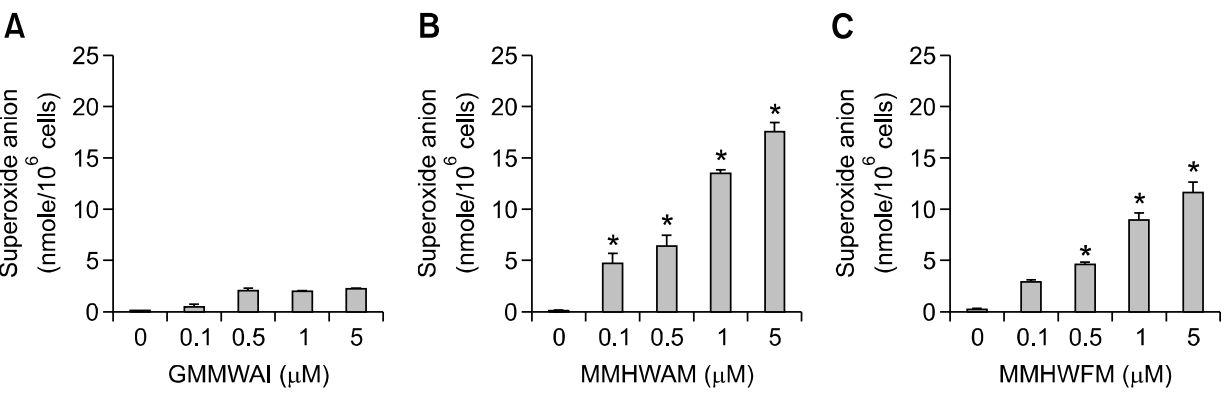

Figure 5. Effects of peptides on superoxide anion production in human neutrophils. Human neutrophils were stimulated with various concentrations of GMMWAI, MMHWAM, or MMHWFM, and the amount of generated superoxide was measured using cytochrome $c$ reduction assay. The data are presented as mean \pm S.E. of three independent experiments, each performed in duplicate. ${ }^{*} P<0.01$ versus vehicle treatment.

A

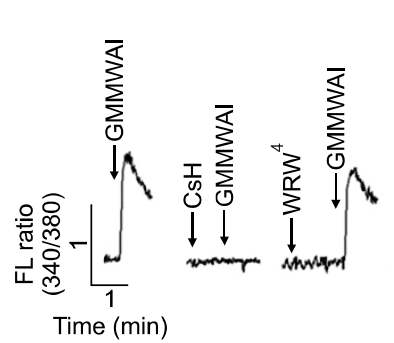

D

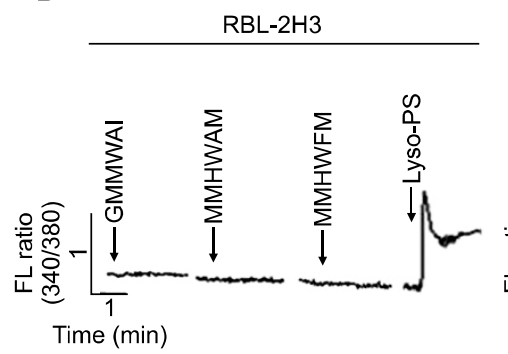

B

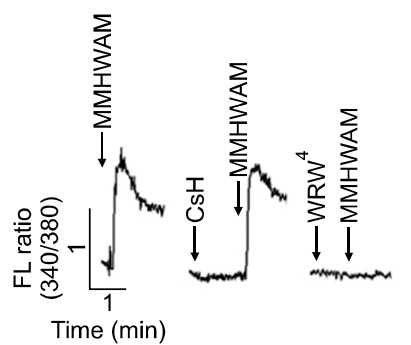

$\mathbf{E}$

FPR1/RBL-2H3
C

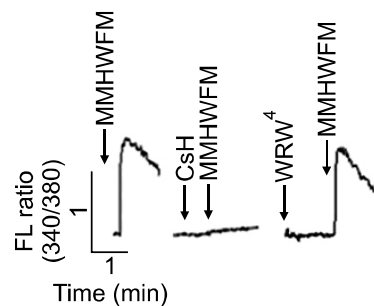

$\mathrm{F}$

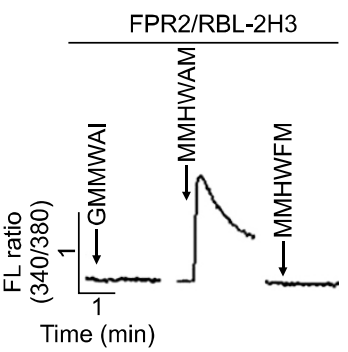

Figure 6. Role of FPR1 or FPR2 in novel peptide-induced $\mathrm{Ca}^{2+}$ increase. Isolated human neutrophils were incubated in the presence or absence of $10 \mu \mathrm{M} \mathrm{CsH}$ or WRW4 prior to $\mathrm{Ca}^{2+}$ measurement using $5 \mu \mathrm{M}$ GMMWAI (A), $5 \mu \mathrm{M}$ MMHWAM (B), or $5 \mu \mathrm{M}$ MMHWFM (C). Vector- (D), FPR1- $(E)$, or FPR2- $(F)$ expressing RBL-2H3 cells $\left(1 \times 10^{6}\right.$ cells $/ \mathrm{ml}$ of serum-free RPMl 1640 medium) were stimulated with $5 \mu \mathrm{M}$ GMMWAI, 5 $\mu \mathrm{M}$ MMHWAM, or $5 \mu \mathrm{M}$ MMHWFM. The results represent one of two independent experiments. 
chemotactic migration via PTX-sensitive G-protein(s) (Figure 2F and data not shown). Formyl peptide receptors are representative chemoattractant receptors in human neutrophils (Ye et al., 2009). Here, we attempted to determine whether or not the three peptides acted through FPR1 and related receptors. For this purpose, we used FPR1 antagonist (CsH) (de Paulis et al., 1996) and FPR2 antagonist (WRW ${ }^{4}$ ) (Bae et al., 2004). As shown in Figures $6 \mathrm{~A}$ and $6 \mathrm{C}$, GMMWAI- and MMHWFM-induced $\mathrm{Ca}^{2+}$ increases were totally inhibited by $\mathrm{CsH}$ but not by WRW ${ }^{4}$. However, MMHWAM-induced $\mathrm{Ca}^{2+}$ increase was completely blocked by WRW ${ }^{4}$ but not by $\mathrm{CsH}$ (Figure 6B). These results suggest that GMMWAI and MMHWFM stimulated $\mathrm{Ca}^{2+}$ increases via FPR1 but not FPR2. On the other hand, MMHWAM stimulated a $\mathrm{Ca}^{2+}$ increase via FPR2 but not FPR1. We also used vector, FPR1-, or FPR2-expressing RBL-2H3 cells as previously reported (Lee et al., 2008). As shown in Figure 6E, stimulation of FPR1-expressing RBL-2H3 cells with the two novel peptides (GMMWAI and MMHWFM) elicited a dramatic increase in intracellular $\mathrm{Ca}^{2+}$. However, the two peptides did not induce an intracellular $\mathrm{Ca}^{2+}$ increase in vector- or FPR2expressing RBL-2H3 cells (Figures $6 \mathrm{D}$ and $6 \mathrm{~F}$ ). These results strongly indicate that the two peptides (GMMWAI and MMHWFM) stimulated FPR1 but not FPR2, resulting in an increase in $\mathrm{Ca}^{2+}$. For MMHWAM, $\mathrm{Ca}^{2+}$ increase was observed in FPR2expressing $\mathrm{RBL}-2 \mathrm{H} 3$ cells but not in FPR1-expressing RBL-2H3 cells (Figure 6E). The result indicates that MMHWAM acted through FPR2, increasing intracellular $\mathrm{Ca}^{2+}$.

\section{Discussion}

Since neutrophils perform important roles in early defense against invading pathogens and other harmful agents (Borregaard, 2010; Kumar and Sharma, 2010), the identification of agonists that enhance neutrophil function is of paramount importance. Here, we screened hexapeptide combinatorial libraries containing more than 47 million different peptide sequences, and we identified three novel hexapeptides (GMMWAI, MMHWAM, and MMHWFM) that stimulate intracellular $\mathrm{Ca}^{2+}$ increase in human neutrophils. GMMWAI and MMHWFM were shown to have selectivity on FPR1 but not on FPR2. In the case of MMHWAM, the peptide showed selectivity on FPR2 but not on FPR1.

Specific ligands are recognized by specific receptors, and this specificity results from a combination of subtle conformational and amino acid sequence differences. Previously some synthetic hexapeptides, WKYMVm, MFYLPM, HFYLPM, and HFYLPm, which act at two fMLF receptor subtypes have been described (Seo et al., 1997; Bae et al., 2001). In our previous reports, we demonstrated that the $Y$ in the $3^{\text {rd }}$ position of the hexapeptide and the $M$ in the $6^{\text {th }}$ position are important for stimulation of FPR family proteins (Bae et al., 2001). Here, we found that other peptides having different amino acids at the $3^{\text {rd }}$ and $6^{\text {th }}$ positions, such as $\mathrm{H} / \mathrm{M}$ (for $3^{\text {rd }}$ position) and I (for $6^{\text {th }}$ position), showed stimulating activity on FPR family proteins. These results suggest that FPR1 has a broad spectrum of ligand recognition capacity. On the receptor specificity of MMHWAM and MMHWFM, we demonstrated that MMHWFM and MMHWAM acted on FPR1 and FPR2, respectively (Figures 6E and 6F). The result indicates that the $5^{\text {th }}$ amino acid is important for the recognition of the peptides by FPR1 or FPR2.

Since GMMWAI, MMHWAM, and MMHWFM were identified by screening artificially synthesized peptides, we looked for sequence similarities between the novel peptides and known proteins by searching databases (SWISS-PROT and TrEMBL), and found that several bacterial proteins such as aminoacyltransferase femB contained the MMHWFM sequence. At this time, we cannot attach any significance to this sequence homology between our novel peptides and bacterial proteins. However, since FPRs recognize certain patterns derived from pathogens, the information that our peptides carry certain bacterial sequences may provide us useful insights into understanding the pattern involved in the recognition of pathogens.

Even though various chemokines and chemoattractants have been identified, only a few short peptides acting on human leukocytes have been known until now. The previously reported peptides WKYMVm (Seo et al., 1997) and fMLF (Spilberg et al., 1981) have been useful tools for studying neutrophil activation. Here, we demonstrated that the novel peptides GMMWAI, MMHWAM, and MMHWFM stimulate human neutrophils by acting on FPR1 or FPR2 (Figure 6). Therefore, these three peptides can also be used as agonists to study neutrophil activation and signaling.

\section{Methods}

\section{Materials}

Peripheral blood mononuclear cell (PBMC) separation medium (Histopaque-1077) and cytochrome c were purchased from Sigma (St. Louis, MO). Fura-2 pentaacetoxymethylester (fura-2/AM) was purchased from Molecular 
Probes (Eugene, OR). PTX was purchased from Calbiochem (San Diego, CA).

\section{Isolation of leukocytes}

The Institutional Review Board (IRB) of Ajou University Hospital specifically approved this study (approval ID: AJIRB-MED-SMP-10-074). We obtained written informed consent from all participants involved in this study. Peripheral blood leukocytes were isolated from healthy donors. Human neutrophils were isolated according to the standard procedures of dextran sedimentation, hypotonic lysis of erythrocytes, and a lymphocyte separation medium gradient as described previously (Bae et al., 2001). PBMCs were separated on a Histopaque-1077 gradient. After two washings with HBSS without $\mathrm{Ca}^{2+}$ and $\mathrm{Mg}^{2+}$, the PBMCs were suspended in $10 \%$ FBS containing RPMI 1640 and incubated for $60 \mathrm{~min}$ at $37^{\circ} \mathrm{C}$ to allow attachment of monocytes to the culture dish. The cells were washed five times with warm RPMI medium to washout lymphocytes, after which the attached monocytes were collected as described previously (Bae et al., 2001). The isolated human leukocytes were then used promptly.

\section{Cell culture}

NIH3T3 (NIH Swiss mouse embryo fibroblasts), 3Y1 (Rat embryonic fibroblasts), 3T3L1 (preadipocytes), and PC12 (rat adrenal pheochromocytoma) cells were obtained from the American Type Culture Collection (Rockville, MD) and maintained as recommended. The cells were maintained at about $1 \times 10^{6}$ cells $/ \mathrm{ml}$ under standard incubator conditions (humidified atmosphere, $95 \%$ air, $5 \% \mathrm{CO}_{2}, 37^{\circ} \mathrm{C}$ ).

\section{Initial screening of PS-SPCLs and measurement of intracellular $\mathrm{Ca}^{2+}$ increase}

The hexapeptide libraries were obtained from the Peptide Library Support Facility of Pohang University of Science and Technology as described previously (Bae et al., 2001). Finally, 114 peptide pools (Cys was excluded in the construction of the libraries) were individually dissolved in water at a final concentration of $27 \mathrm{nM}$ per peptide sequence in each pool. For initial screening of the PS-SPCLs, we measured the level of $\left[\mathrm{Ca}^{2+}\right]_{i}$ by using Grynkiewicz's method with fura-2/AM (Grynkiewicz et al., 1985). Briefly, prepared cells were incubated with $3 \mu \mathrm{M}$ fura-2/AM at $37^{\circ} \mathrm{C}$ for 50 min in fresh serum-free RPMI 1640 medium under continuous stirring. Then, $2 \times 10^{6}$ cells were aliquoted for each assay in $\mathrm{Ca}^{2+}$-free Locke's solution $(154 \mathrm{mM} \mathrm{NaCl}$, $5.6 \mathrm{mM} \mathrm{KCl}, 1.2 \mathrm{mM} \mathrm{MgCl}_{2}, 5 \mathrm{mM}$ HEPES, pH 7.3, $10 \mathrm{mM}$ glucose, and $0.2 \mathrm{mM}$ EGTA) and incubated with the indicated concentrations of peptide pools (final $50 \mathrm{pM}$ per peptide sequence for the initial screening). Fluorescence changes at the dual excitation wavelengths of $340 \mathrm{~nm}$ and $380 \mathrm{~nm}$ and the emission wavelength of $500 \mathrm{~nm}$ were measured, and the calibrated fluorescence ratio was translated into $\left[\mathrm{Ca}^{2+}\right]_{\text {i. }}$.

\section{Chemotaxis assay}

Chemotaxis assays were performed using multiwell cham- bers (Neuroprobe Inc., Gaithersburg, MD) (Bae et al., 2001). Briefly, prepared human neutrophils were suspended in RPMl 1640 at a concentration of $1 \times 10^{6} \mathrm{cells} / \mathrm{ml}$, and $25 \mu$ of the suspension was placed into the upper well of a chamber separated by a $3 \mu \mathrm{m}$ polyhydrocarbon filter from the lower well containing peptides. After incubation for 90 minutes at $37^{\circ} \mathrm{C}$, non-migrated cells were removed by scarping, and cells that migrated across the filter were dehydrated, fixed, and stained with hematoxylin (Sigma, St. Louis, MO). Stained cells in five randomly chosen high power fields $(400 \mathrm{X})$ in the well were then counted (Bae et al., 2001).

\section{Measurement of superoxide anion production}

Superoxide anion generation was determined by measuring cytochrome $c$ reduction using a microtiter 96-well plate ELISA reader (Bio-Tek instruments, EL312e, Winooski, VT), as previously described (Bae et al., 2001). Human neutrophils $\left(2 \times 10^{6}\right.$ cells in RPMI 1640 medium) were preincubated with $50 \mu \mathrm{M}$ cytochrome $\mathrm{c}$ at $37^{\circ} \mathrm{C}$ for $5 \mathrm{~min}$ and subsequently incubated with each peptide. Superoxide generation was determined by measuring light absorption changes at $550 \mathrm{~nm}$ over $5 \mathrm{~min}$ at $1 \mathrm{~min}$ intervals.

\section{Statistical analysis}

The results are expressed as mean $\pm \mathrm{S}$. E. of data obtained from the indicated number of experiments performed. Statistical significance was determined using the Student $t$ test.

\section{Acknowledgements}

This research was supported by the Basic Science Research Program through the National Research Foundation of Korea (NRF) funded by the Ministry of Education, Science and Technology (2010-0020940), by National Research Foundation of Korea (NRF) grant funded by the Korean government (MEST) (No. 2009 0093198), and Samsung Research Fund, Sungkyunkwan University, 2011.

\section{References}

Aramburu J, Yaffe MB, Lopez-Rodriguez C, Cantley LC, Hogan PG, Rao A. Affinity-driven peptide selection of an NFAT inhibitor more selective than cyclosporin A. Science 1999;285:2129-33

Badolato R, Johnston JA, Wang JM, McVicar D, Xu LL, Oppenheim JJ, et al. Serum amyloid A induces calcium mobilization and chemotaxis of human monocytes by activating a pertussis toxin-sensitive signaling pathway. J Immunol 1995;155:4004-10

Bae YS, Kim Y, Kim Y, Kim JH, Suh PG, Ryu SH. Trp-Lys-TyrMet-Val-D-Met is a chemoattractant for human phagocytic cells. J Leukoc Biol 1999;66:915-22

Bae YS, Bae H, Kim Y, Lee TG, Suh PG, Ryu SH. Identification of novel chemoattractant peptides for human 
leukocytes. Blood 2001;97:2854-62

Bae YS, Park EY, Kim Y, He R, Ye RD, Kwak JY, et al. Novel chemoattractant peptides for human leukocytes. Biochem Pharmacol 2003;66:1841-51

Bae YS, Lee HY, Jo EJ, Kim JI, Kang HK, Ye RD, et al. Identification of peptides that antagonize formyl peptide receptor-like 1-mediated signaling. J Immunol 2004;173: 607-14

Berridge MJ. Inositol trisphosphate and calcium signaling. Nature 1993;361:315-25

Borregaard N. Neutrophils, from marrow to microbes. Immunity 2010;33:657-70

Burnashev N. Calcium permeability of ligand-gated channels. Cell Calcium 1998;24:325-32

Dahlgren C, Karlsson A. Respiratory burst in human neutrophils. J Immunol Methods 1999;232:3-14

de Paulis A, Ciccarelli A, de Crescenzo G, Cirillo R, Patella $\mathrm{V}$, Marone $\mathrm{G}$. Cyclosporin $\mathrm{H}$ is a potent and selective competitive antagonist of human basophil activation by $\mathrm{N}$-formyl-methionyl-leucyl-phenylalanine. J Allergy Clin Immunol 1996;98:152-64

Dooley CT, Ny P, Bidlack JM, Houghten RA. Selective ligands for the mu, delta, and kappa opioid receptors identified from a single mixture based tetrapeptide positional scanning combinatorial library. J Biol Chem 1998;273:18848-56

Hayashi S, Kurdowska A, Miller EJ, Albright ME, Girten BE, Cohen AB. Synthetic hexa- and heptapeptides that inhibit IL-8 from binding to and activating human blood neutrophils. J Immunol 1995;154:814-24

Houghten RA, Pinilla C, Blondelle SE, Appel JR, Dooley CT, Cuervo JH. Generation and use of synthetic peptide combinatorial libraries for basic research and drug discovery. Nature 1991;354:84-6

Kobayashi Y. The role of chemokines in neutrophil biology. Front Biosci 2008;13:2400-7

Grynkiewicz G, Poenie M, Tsien RY. A new generation of $\mathrm{Ca}^{2+}$ indicators with greatly improved fluorescence properties. J Biol Chem 1985;260:3440-50

Kumar V, Sharma A. Neutrophils: Cinderella of innate immune system. Int Immunopharmacol 2010;10:1325-34

Lee HY, Kim SD, Shim JW, Lee SY, Lee H, Cho KH, et al. Serum amyloid A induces CCL2 production via formyl peptide receptor-like 1-mediated signaling in human monocytes. J Immunol 2008;181:4332-9

Maruyama T, Kanaji T, Nakade S, Kanno T, Mikoshiba K. 2APB, 2-aminoethoxydiphenyl borate, a membrane-pene- trable modulator of Ins $(1,4,5) \mathrm{P} 3$-induced Ca2+ release. J Biochem 1997;122:498-505

Noh DY, Shin SH, Rhee SG. Phosphoinositide-specific phospholipase $\mathrm{C}$ and mitogenic signaling. Biochim Biophys Acta $1995 ; 1242: 99-113$

Owens RA, Gesellchen PD, Houchins BJ, DiMarchi RD. The rapid identification of HIV protease inhibitors through the synthesis and screening of defined peptide mixtures. Biochem Biophys Res Commun 1991;181:402-8

Rhee SG. Regulation of phosphoinositide-specific phospholipase C. Annu Rev Biochem 2001;70:281-312

Rossi F. The O2- -forming NADPH oxidase of the phagocytes: nature, mechanisms of activation and function. Biochim Biophys Acta 1986;853:65-89

Sabroe I, Prince LR, Jones EC, Horsburgh MJ, Foster SJ, Vogel SN, et al. Selective roles for Toll-like receptor (TLR)2 and TLR4 in the regulation of neutrophil activation and life span. J Immunol 2003;170:5268-75

Segal AW, Abo A. The biochemical basis of the NADPH oxidase of phagocytes. Trends Biochem Sci 1993;18:43-7

Seo JK, Choi SY, Kim Y, Baek SH, Kim KT, Chae CB, et al. A peptide with unique receptor specificity: stimulation of phosphoinositide hydrolysis and induction of superoxide generation in human neutrophils. J Immunol 1997;158: 1895-901

Spilberg I, Mehta J, Daughaday C, Simchowitz L. Determination of a specific receptor for formyl-methionylleucyl-phenylalanine on th pulmonary alveolar macrophage and its relationship to chemotaxis and superoxide production. J Lab Clin Med 1981;97:602-9

Tiffany HL, Lavigne MC, Cui YH, Wang JM, Leto TL, Gao JL, et al. Amyloid-beta induces chemotaxis and oxidant stress by acting at formylpeptide receptor 2 , a $\mathrm{G}$ protein-coupled receptor expressed in phagocytes and brain. J Biol Chem 2001;276:23645-52

Walther A, Riehemann K, Gerke V. A novel ligand of the formyl peptide receptor: annexin I regulates neutrophil extravasation by interacting with the FPR. Mol Cell 2000;5: 831-40

Ye RD, Boulay F, Wang JM, Dahlgren C, Gerard C, Parmentier M, et al. International Union of Basic and Clinical Pharmacology. LXXIII. Nomenclature for the formyl peptide receptor (FPR) family. Pharmacol Rev 2009;61:119-61

Zhu MX, Ma J, Parrington J, Calcraft PJ, Galione A, Evans AM. Calcium signaling via two-pore channels: local or global, that is the question. Am J Physiol Cell Physiol 2010;298: C430-41 